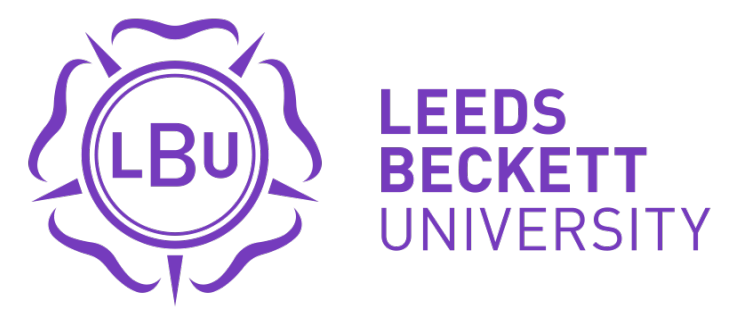

Citation:

Peters, R and Brooks, R (2016) Parental perspectives on the transition to secondary school for students with Asperger syndrome and high-functioning autism: A pilot survey study. British Journal of Special Education, 43 (1). 75 - 91. ISSN 0952-3383 DOI: https://doi.org/10.1111/1467-8578.12125

Link to Leeds Beckett Repository record:

https://eprints.leedsbeckett.ac.uk/id/eprint/2364/

Document Version:

Article (Updated Version)

The aim of the Leeds Beckett Repository is to provide open access to our research, as required by funder policies and permitted by publishers and copyright law.

The Leeds Beckett repository holds a wide range of publications, each of which has been checked for copyright and the relevant embargo period has been applied by the Research Services team.

We operate on a standard take-down policy. If you are the author or publisher of an output and you would like it removed from the repository, please contact us and we will investigate on a case-by-case basis.

Each thesis in the repository has been cleared where necessary by the author for third party copyright. If you would like a thesis to be removed from the repository or believe there is an issue with copyright, please contact us on openaccess@leedsbeckett.ac.uk and we will investigate on a case-by-case basis. 


\title{
Parental Perspectives on the Transition to Secondary School for Students with Asperger Syndrome and High Functioning Autism: A Pilot Survey \\ Study
}

\author{
Rachel Peters and Rob Brooks
}

\begin{abstract}
The transition to secondary school is a common cause of stress, which can be exacerbated by innate characteristics associated with Asperger Syndrome (AS) and high functioning autism (HFA). This study aimed to explore experiences of the transition to secondary school for students with AS/HFA from the parental perspective. Seventeen parents of children with AS/HFA from the north of England completed an online questionnaire about their child's transitional experience. Responses indicated that there are a number of factors that influenced the experience of pupils' with AS/HFA at school and the preceding transition, including anxiety, bullying, friendship and support at school. Girls with AS/HFA presented with unique issues not commonly seen in the male dominated condition. The transition to secondary school was seen to encompass a number of difficulties for students with AS/HFA. Health and educational services can learn from the experiences explored in this survey on order to inform future practice.
\end{abstract}

\section{Introduction}

School is a central aspect of a young person's life. In the UK, education is compulsory for children from the age of five to 16; with children typically spending six or more hours a day, five days a week in school (DfE, 2014). The role of a student encompasses substantially more than classroom learning, with approximately one third of the time at school spent outside of the formal classroom (Wainscot et al., 2008). The school experience also includes a wide range of meaningful activities such as playing at break time, participating in organised activities, being with friends and completing homework. These are fundamental aspects of the educational experience, and contribute to the wellbeing of students at school (Hinder \& Ashburner, 2010). Students with Asperger Syndrome (AS) and high functioning autism (HFA), however may experience barriers to participating in school activities due to the nature of their difficulties. AS/HFA is a subgroup on the autism spectrum; a developmental disability that is associated with impairments in communication, social interaction and flexibility of thinking, commonly termed as the triad of impairments (Attwood, 2007). Students with AS/HFA typically have average to above-average intelligence, which can mask the difficulties experienced at school (Portway \& Johnson, 2005). Despite this, however, children with AS/HFA are 
likely to need additional support both inside and outside of the classroom in order to enhance participation and optimise their educational experience (Humphrey \& Lewis, 2008). Specific barriers to participating in every day school activities for students with AS/HFA are largely connected to the triad of impairments, including poor social skills, high levels of anxiety, sensory processing issues and the absence of a peer companion (Little et al., 2014). Enabling participation in these everyday school activities is important for fostering the student's sense of belonging, in addition to being fundamental for the development of a child's physical, cognitive, social and affective health (Hinder \& Ashburber, 2010).

The transition from primary to secondary school is an educational milestone that encompasses substantial changes to the physical, organisational and social environment (Tobin et al., 2012; Adreon \& Stella, 2001; Dixon \& Tanner, 2013). As a result of these changes, this transition to secondary school is regarded as one of the most difficult in an individual's educational career, commonly causing a considerable amount of stress, worry and anxiety (Zeedyk et al., 2003). Furthermore, in the UK, the beginning of secondary school (ages 11/12) typically coincides with students undergoing developmental changes associated with the onset of puberty. These pubertal changes are exacerbated by an increase in expectations of pupil's academic and social ability when entering secondary school (Dillon \& Underwood, 2012). The majority of the research conducted on the transition to secondary school considers the experiences of typically developing pupils and those with a wide range of special educational needs (Dann, 2011). Research suggests that the majority of students will express some degree of concern and/or anxiety about this transition; however, it is often reported to be of short duration (West et al., 2010). Getting lost, bullying, and an increased workload are common concerns that have been reported by typically developing students (Waters et al. 2014). Nonetheless, secondary school has also been associated with proving a number of opportunities, with students most looking forward to creating new friendships, experiencing new academic subjects, as well as engaging with new teachers and routines (Zeedyk et al., 2003). According to Dann (2011), the concerns raised by students with ASD regarding the transition to secondary school resembled those in the wider transition literature. The difference that emerged was related to the greater intensity and duration of the anxiety associated with the transition (Dann, 2011).

Students with poor social skills have been found to be at greater risk of experiencing adjustment problems and negative feelings of self-worth during the transition (Sofronoff et al., 2011; Symes \& Humphrey, 2010). Difficulties with social skills and communication are characteristics of AS/HFA, which subsequently places these students at high risk for a difficult transition (Dixon \& Tanner, 
2013). Sixty percent of students with ASD are currently educated in mainstream schools, the majority of which have HFA (Dillon et al., 2014). However, at present, a limited amount of research exists that explores the experiences of pupils with AS/HFA in mainstream secondary schools or the preceding transition. Therefore, the aim of this study is to utilise parental perspectives to explore the experiences of students with AS/HFA at secondary school and during the preceding transition that will guide future educational and occupational therapy practice.

\section{Methodology}

\section{Questionnaire}

The purpose of the questionnaire was to explore parental perceptions of their child's experience during the transition to secondary school in order to capture self-reported observations of the support provided throughout this process. The survey comprised of five sections: demographic information, transition to secondary school, life at school, social and leisure activities, and overall feelings about the transitional experience. There were a range of closed-ended questions, including dichotomous, multiple choice and Likert scales (Sue \& Ritter, 2012). Neutral options were provided in the Likert scales as a way to reduce the risk of respondent irritability, which has be correlated with non-response bias (Rattray \& Jones, 2007). Open-ended questions were incorporated to allow respondents to expand on their experience, and to elicit unexpected answers; however were used sparingly in order to maintain respondent interest and attention (Sue \& Ritter, 2012).

The questionnaire was created by the researcher based on the literature surrounding the characteristics of AS/HFA, transitions to secondary school, and autism specific transition checklists in order to assure face and content validity (Rattray \& Jones, 2007). These resources emphasised the aspects of secondary school in which students with AS/HFA may find difficult without the proper support. The survey was piloted with two parents and two professionals working with young people with autism prior to being sent to the gatekeeper organisations.

\section{Participants/Recruitment}

In order to gain access to the specific population, recruitment was conducted via purposeful sampling through the use of organisations as gatekeepers (Braun \& Clarke, 2013). The use of gatekeeper organisations has been recognised as having multiple benefits due to the existing relationships and trust already established with the participants (Thomas et al, 2007). Organisations listed under 'Support Groups and Networks' in The National Autistic Society's service directory in a county in northern England were contacted by e-mail to gain organisational approval to act as a gatekeeper. The category 'Support Groups and Networks' was chosen because it encompassed 
groups and organisations that contained both family support as well as groups targeting socialisation and social skills.

A total of 37 organisations were contacted by e-mail. The organisational response rate was $40.5 \%$ $(n=15) .8$ of the 15 organisations confirmed they had members in the appropriate age group and agreed to publicise the information regarding the questionnaire for their clients, via e-mail, social media and in newsletters.

The inclusion criteria for participation required participants to be the parents or guardians of students with a diagnosis of AS/HFA, currently in Year 7 or 8 at a mainstream school in the UK. Interested parents were directed to a secure URL on SurveyMonkey, where they could read the information sheet, confirm their eligibility and provide informed consent before proceeding to the questionnaire. The questionnaire was completed anonymously, and did not require disclosure of any personal details. The questionnaire was available online through SurveyMonkey for a total of three months.

The parental perspective was utilised for this study in order to capture the experience of the transitional process and the observable outcomes of the transition to secondary school for young people with AS/HFA. Furthermore, the literature emphasises that the parents of young people with disabilities are frequently profoundly involved in the transitional process, acting as an advocate for the pupil (Dixon \& Tanner, 2013).

Responses

There were a total of 19 responses, however the majority of questions for two participants were left incomplete therefore they were not included in the analysis ( $n=17$ in analysis). The vast majority of the respondents classified themselves as the mother (70.6\%), with the remaining participants identifying themselves as father (11.8\%) and parent (17.6\%). Of the students discussed in the survey, there were 14 males and three females, all of which were Caucasian.

Analysis

The survey contained questions that comprised of both quantitative and qualitative data. Quantitative data was coded and inputted into Microsoft Excel to calculate systematically the correlation coefficient between the variables (Sue \& Ritter, 2012). The survey data were analysed through pattern based analysis, in order to determine features and themes across the dataset (Braun \& Clarke, 2013). Full thematic analysis was not appropriate for this data due to the length of the responses. 


\section{Findings}

The findings of the study have been divided into five sections based on the structure of the questionnaire: the transition, life at school, social and leisure participation, parental opinion and quantitative findings.

\section{The Transition}

The questionnaire elicited results that demonstrated a range of transitional experiences and a number of factors that influenced the ease of the transition. Structured transition planning (for example meetings, organised visits) occurred for $76 \%$ of the respondents, with the primary school generally being responsible for the initiation of this. Consequently, $29 \%$ of parents had to initiate the planning of the transition and/or request additional visits to the secondary school. The most frequently reported tools utilised by schools to assist with the transition were a visit day for all students in Year 6 to the secondary school (100\%) and transition planning meetings with both schools (40\%). Initially, in an open ended question, half of the respondents stated that the transition went well. However, nearing the end of the survey, when asked to rate the transition on a 5 point Likert scale $(1=$ extremely easy to $5=$ extremely difficult), the average rating for the transition fell between difficult and neither difficult nor easy (mean $=2.75$; median $=3)($ See figure 1$)$.

Figure 1

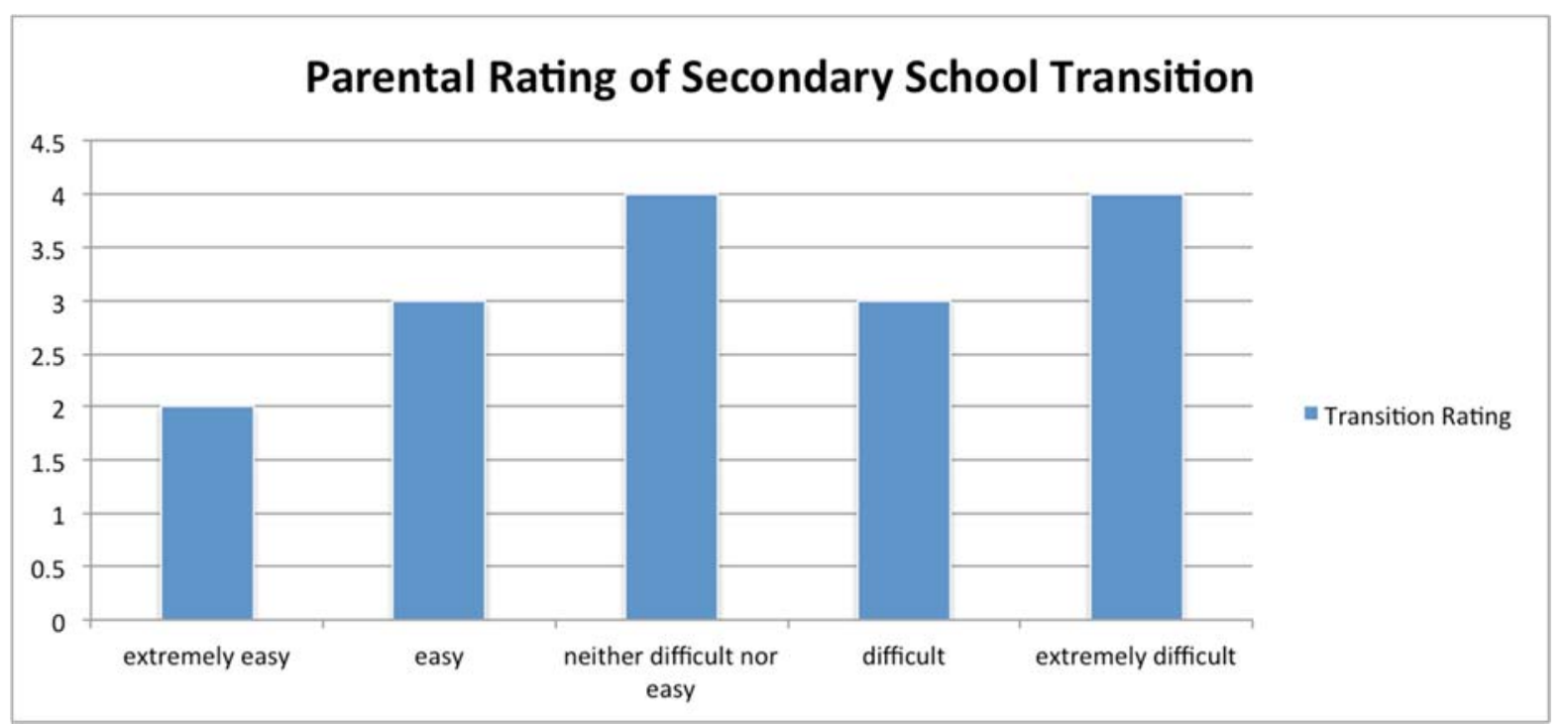

The parents of students whose transition was rated 'extremely easy' or 'easy' $(n=5)$, reported receiving supplementary pre-transitional visits in Year 6 and support once commencing secondary school. However, the parents of students whose transition was rated as extremely difficult $(n=4)$ 
uniformly received minimal transitional support, but also reported additional stressors influencing their experience (e.g. bullying, severe anxiety).

The apprehensions parents revealed about their child's transition to secondary school were related to a change in routine/environment and relationships. The study showed that $65 \%$ of parents feared how their child would manage with the new routine and environment of secondary school. Peer interaction and forming new relationships were indicated by $70 \%$ of the parents' as being their primary concern for their child prior to starting secondary school. Furthermore, $53 \%(n=9)$ of parents reported suspicions that their child was being bullied at school.

\section{Life at School}

The majority of students (87.5\%) were reported to be experiencing difficulties at school. The most frequently recounted difficulties related to concentration, academics (including homework), boredom, bullying/peer relationships and stress/anxiety. Anxiety was shown to be the greatest concern for students, with $\mathbf{8 7 . 5 \%}$ experiencing anxiety at school in general. Two female students began to experience difficulties with constipation and incontinence during Year 7; the parents accredited this to increased anxiety. Periods of the students' day that were emphasised as particularly stressful were: the commute to school, physical education, lunch/break time and transitioning between classes. The coping mechanisms at school recurrently involved "switch[ing] off" into their own world through listening to music or playing a video/computer game or seeking solitude or a quiet space within the school environment. Furthermore, academics were stated to be a challenging area for $71 \%$ of students in Year 7 , with organisation and a lack of clarification given for homework being specified as a significant stressor. Forty-four percent of parents indicated that teachers do not alter their teaching style to suit and support the individual needs of students.

\section{Social and Leisure Participation}

The questionnaire indicated that participation in organised school clubs and activities was low for students with AS/HFA. Seventy-six percent of the students do not participate in any school clubs or activities. At break time, parents reported that 10 out of 16 students either partake in an individual activity (reading a book, using a computer etc.) or go to a special needs/designated room. The other leisure activities described in the survey predominantly comprised playing videogames or playing on the computer $(62 \%, \mathrm{n}=10$ out of 16$)$.

Creating new friendships was indicated as being difficult for $62.5 \%$ of the pupils. Half of the students were said to have between $0-2$ friends, $37.5 \%$ between $3-5$ and $12.5 \%$ between $6-10$ friends. The 
quality of the friendships varied between 'acquaintances' or 'school mates only' to 'very good'. 4 out of the 9 friendships that were rated either good or very good were with other students with ASD.

\section{Parental Perspective}

Two open-ended questions sought to explore what the parents: (1) would like schools to do to support students with AS/HFA during the transition, and (2) would like educators to know about AS/HFA. The most prevalent response for recommended transitional support was arranging additional visits during Year 6, including a summer school or camp at the secondary school. Fifty percent of parents emphasised the importance for educators to understand that each child is unique. Parents also stated that teacher education was important in order for teachers to understand the reason behind specific behaviours and that with the right support, students with AS/HFA can excel.

\section{Quantitative Findings / Correlational Analysis}

Pearson correlations $(r)$ were calculated for all quantitative variables. Students' self-esteem was found be rated higher when they were receiving academic support $(r=0.80)$; when they enjoyed school $(r=0.82)$ and if they had a more positive transition experience $(r=0.71)$. Having adequate social support, on the other hand, was not found to have the same relationship with self-esteem ( $r=$ 0.63). No significant correlations were found in relation to the other variables.

\section{Discussion}

This research set out to examine the parental perspectives regarding the transition to secondary school for students with AS/HFA. The results highlight many contemporary areas of discussion within the field of education and ASD studies, including the experience of anxiety, social engagement, as well as the receipt of transitional and educational support. The main overall finding of this study illustrated that there is no one overarching problem that will dictate whether a student with AS/HFA has a smooth transition to secondary school. Instead, the responses indicate that there are a number of factors that influence the pupil's experiences throughout this transitional period.

\section{Anxiety}

Anxiety emerged in the current study as a significant issue for students with AS/HFA. Literature has recognised anxiety as an evident concern for this population as there is a higher reported prevalence than typically developing pupils and those with learning disabilities (Humphrey \& Lewis, 2008; White et al., 2009). There are explicit long-term implications of anxiety documented in the literature, including experiences of underachievement in school and employment, as well as an increased risk 
of mental health difficulties (Portway \& Johnson, 2005). High levels of stress and anxiety prompted educational disruption for a female student in this study whose father recounted that, the "stress of the whole school experience led to having to take her out [of school]" (Participant (P)25). Anxiety can consequently impact participation and future achievements, thus reiterating the need for the provision of support to be pre-emptive.

Parents in this study reported student stress and anxiety during a range of activities associated with secondary school, including the commute to school, class transitions, physical education and unstructured times such as break and lunchtime. The stressful times of day are similar to those reported in the literature (Davis, 2009; Waters et al., 2014); however, the findings of this study provide brief insight into the manifestations of stress and anxiety. Some of the male students were reported to have "meltdowns", "switch[ing] off into [their] own world", as well as requiring to be accompanied into the school to manage anxiety. Two-thirds of the female students on the other hand, experienced levels of stress and anxiety that resulted in physical manifestations including bouts of constipation and incontinence; research suggests that females with AS/HFA are more likely to exhibit internalising behaviours rather than displaying challenging or aggressive ones (Solomon et al., 2012). This is further supported in the current study as internalising behaviours, specifically depressive symptoms and self-harm, were exclusively reported to be exhibited by the female students. A father emphasised this unique experience, stating that girls with AS/HFA can present with different behaviours to cope with stress than their male counterparts. The experiences of females with the condition has been largely overlooked in the literature; something which has been attributed to the male predominance in the ASD population. Cridland et al. (2014) explored the female experience and concluded that adolescent girls have distinct challenges, including: developing and maintaining friendships, sex-specific puberty issues and living with a disorder that is largely associated with boys. However, this study found that the main issues were concerned with internalising behaviours and the physical manifestations of psychological issues. Although the findings differ from those of Cridland et al. (2014), this study adds valuable knowledge to a growing field of research surrounding this topic.

\section{Social Engagement}

The findings of this study compliment current research, in that this population tends to engage in a limited number of activities within school and in the community, the majority of which are done solitarily (Little et al., 2014; Wainscot et al., 2008). Little et al. (2014) found that in comparison to typically developing children and those with other developmental disabilities, students with AS/HFA spent more time inside during breaks, had fewer social interactions during the school day and 
limited, if any, participation in school clubs. The influences effecting participation were not specifically explored in this study; however, literature considers the influence and dynamic interaction of the physical and social environment, as well as the impact that pupil's interests, motivation and abilities have in supporting or hindering their involvement (Coster et al., 2013).

The analysis of leisure activities can shed light on what the students in this study typically participate in, and on the reasoning behind these choices. Consistent with the findings by Kuo et al. (2013), the most prevalent leisure activities reported in this study was playing video games and playing on the computer. Video games were revealed as being an activity utilised for some as a form of escapism, and for others as a way to socialise with friends. This suggests that for individuals with AS/HFA, video games have the potential to create a context for socialisation, acting as a "social bridge" (Kuo, 2013, p. 495). The popularity of video games in this study was more commonly attributed to boys; with the girls reporting engagement in more physically exertive activities, including walking, cooking and biking. Participation in everyday activities, both formal and informal, has been proven to have a substantial impact on promoting learning and development, in addition to influencing long term mental and physical health outcomes (Hilton et al., 2008; Law et al., 2006).

The social experience of young people in secondary school is often reported as being more important to the student than academic success, as it promotes a sense of personal belonging and acceptance (Poulsen \& Ziviani, 2010). Despite the commonality of partaking in solitary activities, many students with AS/HFA seek friendships and express feelings of loneliness in the school environment (Sofronoff et al., 2011). Subsequently, students with AS/HFA in mainstream schools have been found to be at the greatest risk for peer victimisation and bullying due to their poor social and communication skills, having fewer friends and being less protected in the mainstream education system (Zablotsky et al., 2014). In this study, just over 50\% of the parents reported that they had suspicions that their child gets bullied at school, compared to the research reported by Carter (2009), who found that nearly $65 \%$ of parents suspected this. Bullying is associated with increased exposure and vulnerability to social isolation and behavioural issues at school; difficulties to which students with AS/HFA are already prone to (Sofronoff et al., 2011; Hebron \& Humphrey, 2014).

Difficulties in establishing and maintaining peer relationships for adolescents with AS/HFA are well established in the literature (Sofronoff et al., 2011; Humphrey \& Lewis, 2008). The number of friends reported in this study ranged from 0 to 10 , with half of the respondents indicating between 0 and 2 friends. This is substantially lower than the rates found by Wainscot et al. (2008), with the mean number of friends for pupils with AS being eight. Nonetheless, the number of friendships reported 
by the control group in the study by Wainscot et al. (2008), was significantly higher (mean $=25$ ) than the numbers expressed by the pupils with AS. The current study utilised the parental perception of the number of friendships, whereas Wainscot et al. (2008) reported the student perspective. The variance in numbers therefore may be associated with the difference between the parent's and student's perception of what constitutes a friendship (Kuo et al., 2013).

\section{Support}

Support has been documented as central to achieving a positive transition and settling into school life (Evangelou et al., 2008) a finding that was mirrored in this study. Positive transitional ratings were associated in this study with receiving pre-transitional support, particularly through supplementary school visits in Year 6. Similarly, longer or repeated visits to secondary school have been correlated with the facilitation of a smooth transition through familiarising the students with the environment and reducing student anxiety (Tobias, 2009; Tobin et al., 2012).

The present study further suggests, however, that pre-transitional support is not a stand-alone factor influencing the ease of the transition. Rather, stressors relating to the physical and social environment in secondary school, in combination with receiving minimal support, resulted in transitions that were rated as extremely difficult. Stressors, such as bullying, anxiety and a lack of school resources, are factors that could restrict the ability of the students to become comfortable in their new setting, and thus prevent a successful transition (Dixon \& Tanner, 2013). This finding augments transitional literature, illustrating that although pre-transitional visits are beneficial, support needs to be an ongoing process in order to enhance the quality of their school experience.

According to a research report by the Department for Children, Schools and Families, a transition to secondary school is deemed as successful if the young person adapts to the new routines and organisation, causes no concern for their parents, creates new friendships, expresses an academic interest and has improved self-esteem and confidence (Evangelou et al., 2008). The impairments associated with AS/HFA can make these adjustments particularly difficult; therefore support has been recognized as being a key factor to transition (Tobias, 2009). Although academic interest is established as an indicator of a positive transition, the high levels of academic and cognitive ability of young people with AS/HFA often results in their difficulties going unnoticed (Mitchell \& Beresford, 2014). This barrier to support is associated in the literature to the invisible nature of AS/HFA, as well as to teachers and staff not receiving adequate training/education on AS/HFA in order to enable them to identify what support is required (Jackson Brewin et al., 2008; Lindsay et al., 2013). This challenge is illustrated in the current study through the reactive nature of the schools in providing support for it's students. This is reflected in the experience of one mother (P24), whose son's school 
failed to recognise her son's needs and insisted that "there was nothing to worry about with [her] son"; he did not require any support. Support was subsequently only received following parental persistence after her son began experiencing extreme anxiety in Year 7. This high level of parental involvement reflects the literature and has been associated with a lack of support from services and educational staff not receiving sufficient training on ASD and the subsequent effects on behaviour and learning needs (Mitchell \& Beresford, 2014; Lindsay et al., 2014).

\section{Limitations and Future Directions}

The demographics of the sample proved to be a limitation of the study. The absence of a control group limited the comparability of the findings to typically developing pupils. A skewed representation of females in the sample simply reflected the male dominance of the condition. However, this study demonstrated that females with AS/HFA have a unique experience and thus further research is necessary to capture the experience of females with the condition. The ethnicity of the participants in this study was homogenous, and therefore not representative of the population. Research suggests that ethnic minority populations and those of lower socioeconomic status are not widely accessing support services (Slade, 2014; Thomas et al., 2007). Furthermore, access to a computer and the Internet was required to complete the questionnaire, which may have limited participation. Recruitment for future research through schools and additional organisations may be necessary in order to reach a more diverse population, potentially enhancing the understanding of experiences for all students with AS/HFA.

Diagnoses were not verified for this study, which consequently meant that participants may not have had a formal diagnosis or could have been on a different part of the spectrum. Therefore if any participants were not part of the HFA subgroup, this will limit the external validity of the findings. Furthermore, responses were self-reported and retrospective, which could be a potential source of bias. This could be negated in future research by longitudinal, prospective studies and by utilising multiple methods to elicit information.

While the parental perspectives were utilised in this study, it is important for future research also to capture the views of the students and their teachers in order ultimately to obtain a holistic picture and to learn how best to support students with AS/HFA in school. Lastly, this was a small scale study and participants were recruited from one county in England; therefore, geographical bias may be present and may limit the degree to which the findings represent the national landscape. However, a number of the findings are consistent with previous research and, as a result, conducting this research on a national scale would be beneficial. 


\section{Conclusions}

The transition from primary to secondary school is recognised as a significant event, which most students find stressful and anxiety provoking (Zeedyk et al., 2003). Without adequate support, students with AS/HFA can experience barriers to participation in everyday school activities and high levels of stress and anxiety as a result the difficulties that arise from the innate characteristics associated with the condition (Tobin et al., 2012).

The findings from this study demonstrate that the success of a transition is multifactorial, and that consideration needs to be given to the specific individual and his or her environment and personal needs in order to promote inclusion in school, and subsequent wellbeing. A thorough understanding of the student and parental experience is fundamental for professionals working with young people with AS/HFA as it establishes how participation in school activities can be supported and importantly how they are hindered.

The results of this study further demonstrate that the transition to secondary school requires pretransitional preparation, in addition to on-going support throughout secondary school. There are a number of factors that influence this experience, including anxiety, bullying, peer relationships and the level of support received. The difficulty experienced by students with poor transitions further validates the need for a preventative and proactive approach in schools to provide a suitable environment for optimal participation in education and school activities. In order for this to occur, studies have shown that supplementary training on ASD for teachers is vital to enable them to identify how best to support the student's education and school inclusion (Lindsay et al., 2014). Moreover, the experience of girls with AS/HFA was highlighted in this study as an area requiring further research, as their parents reported distinct difficulties compared to the patents of their male counterparts. Students in this study illustrated that a successful transition to secondary school is possible with adequate support; however, without these protective factors, the transition can be catastrophic. By enabling and providing opportunities for students with AS/HFA to participate in all aspects of life at school, educators can enhance inclusion, and support overall wellbeing and development.

\section{References}

Adreon, D. \& Stella, J. (2001) 'Transition to Middle and High School: Increasing the Success for Students with Asperger Syndrome', Intervention in School and Clinic, 36(5), 266-271.

Attwood, T. (2007) 'The Complete Guide to Asperger's Syndrome', London: Jessica Kingsley Publishers. 
Braun, V. \& Clarke, V. (2013) 'Successful Qualitative Research: a practical guide for beginners', London: Sage.

Carter, S. (2009) 'Bullying of Students with Asperger Syndrome', Issues on Comprehensive Pediatric Nursing, 32(3), 145-154.

Coster, W., Law, M., Bedell, G., Liljenquist, K., Kao, Y. Khetani, M. \& Teplicky, R. (2013) 'School participation, supports and barriers of students with and without disabilities', Child: care, health and development, 39(4), 535-543.

Cridland, E., Jones, S., Caputi, P., \& Magee, C. (2014) 'Being a Girl in a Boys' World: Investigating the Experiences of Girls with Autism Spectrum Disorders During Adolescence', Journal of Autism and Developmental Disabilities, 44(6), 11261-1274.

Dann, R. (2011) 'Secondary transition experiences for pupils with Autism Spectrum Conditions (ASCs)', Educational Psychology in Practice, 27(3), 293-312.

Davis, N. (2009) 'Autism and Transition: A Nonlinear Dynamics Systems Perspective', Journal of Occupational Therapy, Schools \& Early Intervention, 2(3-4), 221-237.

DfE (Department of Education) (2014) 'Participation of Young People in Education, Employment or Training: Statutory Guidance for Local Authorities', London: Her Majesty's Government.

Dillon, G., Underwood, J. \& Freemantle, L. (2014) Autism and the U.K. Secondary School Experience, Focus on Autism and Other Developmental Disabilities. [Online before print June 20, 2014]

Dixon, R. \& Tanner, K. (2013) 'The Experience of Transitioning Two Adolescents with Asperger Syndrome in Academically Focused High Schools', Australasian Journal of Special Education, 37(1), 28-48.

Evangelou, M., Taggart, B., Sylva, K., Melhuish, E., Sammons, P. \& Siraj-Blatchford, I. (2008) 'Effective Pre-school, Primary and Secondary Education 3-14 Project: What Makes a Successful Transition from Primary to Secondary School?', London: Department for Children, Schools and Families.

Hebron, J. \& Humphrey, N. (2014) 'Mental health difficulties among young people on autistic spectrum in mainstream schools: a comparative study', Journal of Research in Special Educational Needs, 14(1), 22-32.

Hilton, C., Crouch, M. \& Israel, H. (2008) 'Out-of-school participation patterns in children with high functioning autism spectrum disorders', American Journal of Occupational Therapy, 62(5), 554-563.

Hinder, E. \& Ashburner, J. (2010) 'Occupation-centred Intervention in the School Setting', in S. Rodgers (ed) Occupation-Centred Practice with Children: A Practice Guide for Occupational Therapists. Oxford: Wiley-Blackwell Publishing.

Humphrey, N. \& Lewis, S. (2008) "Make me normal': the views and experience of pupils on the autistic spectrum in mainstream secondary school', Autism, 12(23), 23-46. 
Jackson Brewin, B., Renwick, R. \& Fudge Schormans, A. (2008) 'Parental Perspectives of the Quality of Life in School Environments for Children with Asperger Syndrome', Focus on Autism and Other Developmental Disabilities, 23(4), 242-252.

Kuo, M., Orsmond, G., Cohn, E. \& Coster, W. (2013) 'Friendship characteristics and activity patterns of adolescents with an autism spectrum disorder', Autism, 17(4), 481-500.

Law, M., Petrenchik, T. Ziviani, J. \& King, G. (2006) 'Participation of Children in School and Community', in S. Rodger \& J, Ziviani (eds) Occupational Therapy with Children: Understanding Children's Occupations and Enabling Participation. Oxford: Blackwell Publishing.

Linsday, S. Proulx, M. Thomson, N. \& Scott, H. (2013) Educators' Challenges of Including Children with Autism Spectrum Disorder in Mainstream Classrooms, International Journal of Disability, Development and Education, 60(4), 347-362.

Little, L., Sideris, J., Ausderau, K. \& Baranek, G. (2014) 'Activity Participation Among Children with Autism Spectrum Disorder', American Journal of Occupational Therapy, 68(2), 177-185.

Mitchell, W. \& Beresford, B. (2014) 'Young people with high-functioning autism and Asperger's syndrome planning for and anticipating the move to college: what supports a positive transition?', British Journal of Special Education, 41(2), 151-171.

Portway, S. \& Johnson, B. (2005) Do you know I have Asperger's Syndrome? Risks of a non-obvious disability, Health, Risk \& Society, 7(1), 73-83.

Poulsen, A. \& Ziviani, J. (2010) 'Enablement of Children's Leisure Participation', in S. Rodgers (ed) Occupation-Centred Practice with Children: A Practice Guide for Occupational Therapists. Oxford, Wiley-Blackwell Publishing.

Rattray, J. \& Jones, M. (2007) 'Essential elements of questionnaire design and development', Issues in Clinical Nursing, 16(2), 432-443.

Slade, G. (2014) 'Diverse Perspectives: Challenges for families affected by autism from Black, Asian and Minority Ethnic communities', London: The National Autistic Society.

Sofronoff, K., Dark, E., Stone, V. (2011) 'Social vulnerability and bullying in children with Asperger Syndrome', Autism, 15(3), 355-372.

Solomon, M. ,Miller, M., Taylor, S., Hinshaw, S., Carter, C. (2012) 'Autism Symptoms and Internalising Psychopathology in Girls and Boys with Autism Spectrum Disorder', Journal of Autism and Developmental Disorders, 42(1), 48-59.

Sue, V. \& Ritter, L. (2012) 'Conducting Online Surveys', London: Sage.

Symes, W. \& Humphrey, N. (2010) 'Peer-group indicators of social inclusion among people with autism spectrum disorders (ASD) in mainstream secondary schools', School Psychology International, 31(5), 478-494.

Thomas, K., Ellis, A. McLaurin, C., Daniels, J. \& Morrissey, J. (2007) 'Access to Care for Autism Related Services', Journal of Autism and Developmental Disabilities, 37(10), 1902-1910. 
Tobias, A. (2009) 'Supporting students with autistic spectrum disorder (ASD) at secondary school: a parent and student perspective', Educational Psychology in Practice, 25(2), 151-165.

Tobin, H., Staunton, S., Mandy, W., Skuse, D., Hellriegel, J., Baykaner, O., Anderson, S. \& Murin, M. (2012) 'A qualitative examination of parental experiences of the transition to mainstream secondary school for children with an autism spectrum disorder', Educational \& Child Psychology, 29(1), 75-85.

Wainscot, J., Naylor, P., Sutcliffe, P., Tantrum, D. \& Williams, J. (2008) 'Relationships with Peers and Use of School Environment of Mainstream Secondary School Pupils with Asperger Syndrome (High Functioning Autism): A Case-Control Study', International Journal of Psychology and Psychological Therapy, 8(1), 25-38.

Waters, S., Lester, L. \& Cross, D. (2014) 'Transition to secondary school: expectation versus experience', Australian Journal of Education, 58(2), 153-162.

West, P., Sweeting, H. \& Young, R. (2010) 'Transition matters: pupils' experiences of the primarysecondary school transition in the West of Scotland and consequences for well-being and attainment', Research Papers in Education, 25(1), 21-50.

White, S. W., Oswald, D., Ollendick, T. \& Scahill, L. (2009) 'Anxiety in children and adults with autism spectrum disorder', Clinical Psychology Review, 29(3), 216-29.

Zablotsky, B., Bradshaw, C., Anderson, C. \& Law, P. (2014) 'Risk factors for bullying among children with autism spectrum disorders', Autism, 18(4), 419-427.

Zeedyk., M., Gallacher, J. Henderson, M., Hope, Gillian, H., Husband, B. \& Lindsay, K. (2003) 'Negotiating the Transition from Primary to Secondary School: Perceptions of Pupils, Parents and Teachers', School Psychology International, 24(1), 67-78. 